\title{
The antimicrobial efficacy of Fijian honeys against clinical isolates from diabetic foot ulcers
}

\author{
Rajneeta Saraf ${ }^{1 *}$, Vincent Bowry ${ }^{1}$, Dhana Rao ${ }^{1}$, Prashant Saraf ${ }^{2}$ and Peter Molan ${ }^{3}$ \\ ${ }^{1}$ School of Biological, Chemical and Environmental Sciences, University of the South Pacific, Fiji. \\ ${ }^{2}$ A\&E Department, CWM Hospital, Suva, Fiji. \\ ${ }^{3}$ Honey Research Unit, Department of Biological Sciences, University of Waikato, New Zealand.
}

Received 10 October 2008, accepted subject to revision 27 March 2009, accepted for publication 1 May 2009.

*Corresponding author: Email: rajneetaraj@hotmail.com

\section{Summary}

A diverse range of illnesses has been treated with honey since ancient civilizations. There has been growing interest by health care professionals in wound care products based on New Zealand manuka honey and Australian honey of similar Leptospermum spp. In Fiji, local honeys have been used in homes to treat diabetic foot ulcers which have failed to heal by conventional therapeutic methods. This suggests that Fiji honeys may confer antimicrobial activity against the isolates from diabetic foot ulcers and this inference was tested in this study. The antimicrobial activity of 30 natural and two processed honeys was determined using some clinical isolates from diabetic foot ulcers, namely: Staphylococcus aureus, Escherichia coli, Proteus mirabilis, Pseudomonas aeruginosa, Klebsiella pneumoniae and Candida albicans. The antimicrobial activity of the natural honeys, determined by an agar well diffusion assay and expressed as the concentration of phenol with equivalent activity, was found to be between 4.1 and $14.5 \% \mathrm{w} / \mathrm{v}$ phenol. The mean inhibitory concentrations (MIC) of the honeys determined by an agar incorporation technique, was found to range from $4.8 \%$ to more than $9.1 \%(\mathrm{v} / \mathrm{v})$ honey $(9.1 \%$ being the highest concentration tested). In comparison, the activities of two processed honeys were between $4.5-8.9 \%$ phenol equivalence and did not inhibit the clinical isolates from diabetic foot ulcers at the highest concentration of honey tested (9.1\%). The results demonstrate that Fijian honeys could be utilized as a herbal remedy for the treatment of diabetic foot ulcers. However, to assess the potential of Fijian honeys on diabetic foot ulcers, there is a need for clinical trials on these wounds.

Keywords: Diabetic foot ulcers, antibacterial activity, mean inhibitory concentration, honey, Staphylococcus aureus, Pseudomonas aeruginosa, Escherichia coli, Proteus mirabilis, Klebsiella pneumonia, Candida albicans.

\section{Introduction}

Although honey is known as a food, there is growing interest in the medicinal properties of honey and its role in the treatment of many different health problems. Honey has many therapeutic properties; however the antibacterial property of honey is one which has evoked great interest among researchers. The antimicrobial property of honey is dependent on several contributing factors. Low water content, high osmolarity (high sugar content) and low pH prevent the growth of many bacteria but do not fully account for the activity of the honeys. The hydrogen peroxide and non-peroxide phytochemical) components of honey contribute to its additional activity (Molan, 1992). About $70 \%$ of honey's natural sugars are made up of glucose and fructose. The enzyme glucose oxidase which is introduced to the honey during nectar collection acts on glucose and produces gluconic acid and hydrogen peroxide upon dilution (White et al., 1963). In many honeys, heating at elevated temperatures destroys this hydrogen peroxide activity and it is also lost in the presence of catalase (an enzyme that degrades hydrogen peroxide and is present in wound fluid). Honeys that retain activity in the presence of catalase are said to have non-peroxide antibacterial activity, manuka honey from New Zealand being an example of a 
honey with a high level of such activity (Allen, et al., 1991).

There is increased development of resistance to every antibiotic introduced in clinical practice (Payne et al., 2007). Wound infections caused by drug-resistant organisms are common and lead to increased costs, morbidity and mortality. There is an urgent need for the discovery of new antibiotics with novel modes of action. Honey has been utilized as a wound care product and its usage as a wound healing agent is reported in the treatment of venous leg ulcers (Gethin \& Cowman, 2008; Jull et al., 2008), burns (Subramanian, 1993), chronic leg ulcers (Oluwatosin et al., 2000), pressure ulcers (Weheida et al., 1991) and exit sites of central venous catheters (Johnson et al., 2005). There has been growing interest by health care professionals in wound-care products based on New Zealand Manuka honey and Australian honey of similar Leptospermum spp. (Molan and Betts, 2004). In Fiji, local honeys have been used in homes to treat diabetic foot ulcers (DFU) which have failed to heal by conventional therapeutic methods. This suggests that Fiji honeys may confer antimicrobial activity against the species infecting DFU and this inference was tested in this study.

Infected foot ulcers are a common cause of morbidity in diabetic patients leading to complications like gangrene and amputations. In Fiji, one in every five people has diabetes and the incidence of foot problems and amputations remains high. Full thickness penetration of the dermis of the foot of diabetic people allows colonization of microbial species and initiates a complex series of reactions which leads to transient wound contamination or clinical infection. The initial microbial burden is low in DFU; however lack of proper care promotes microbial density and diversity. Most of the DFU are polymicrobial in nature (Brodsky et al., 1991; Ramani et al., 1991; Criado et al., 1992; Pathare et al., 1998; Chincholikar \& Pal, 2002; Viswanathan et al., 2002). It has been reported that the prevalence of Staphylococcus aureus amongst Gram-positive bacteria and Pseudomonas aeruginosa amongst Gram-negative bacteria were the most dominant of the flora of DFU, followed by Klebsiella pnuemoniae, Escherichia coli, Proteus mirabilis and Candida albicans, (Bansal et al., 2008).

There are many published reports on the antimicrobial potency of honey against different microbes and some of these studies have included S. aureus (Cooper et al., 1999; Cooper et al., 2002; Miorin et al., 2003; Al Waili, 2004; French et al., 2005; Basualdo et al., 2007; Mercan et al., 2007), P. aeruginosa (Cooper et al., 2002; Estrada et al., 2005; Boukraa et al., 2007; Mercan et al., 2007; Mullai \& Menon., 2007), E. coli (Estrada et al., 2005; Fangio et al., 2007; ), K. pnuemoniae (Al Waili, 2004; Estrada et al., 2005; Mercan et al., 2007), P. mirabilis (Al Waili, 2004; Estrada et al., 2005) and Candida species (Estrada et al., 2005; Mercan et al., 2007).

The aim of the present study was to compare the antimicrobial capacity of 30 unprocessed Fijian honeys produced by

\section{The Map of Fiji Islands V A N U A L E V U Northern Division: \\ YASAWA GROUP

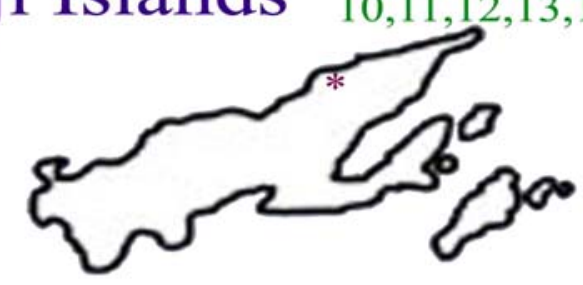 10 Malawai Dreketi 11 Nabita Dreketi 12 Dreketi Village \\ TAVEUNI 3 Batiri 15 Dalielawa Dreketi $0^{\circ}$ \\ 0

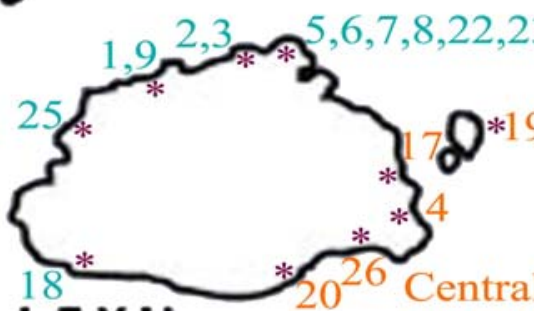 \\ 24 \\ 15 Dogotuki Lambasa \\ VITI LEVU \\ Western Division: \\ 18 Navosa Sigatoka \\ 25 Processed Honey \\ 1 Yalalevu, Ba \\ 9 Vutuni, Ba \\ 2,3 Tavua \\ 5,6,7,8,24 Rakiraki \\ 22 Yaqara Rakiraki \\ 23 Town Rakiraki \\ - 20 Serua Navua \\ NOUA \\ 26 Processed Honey Nakasi Suva

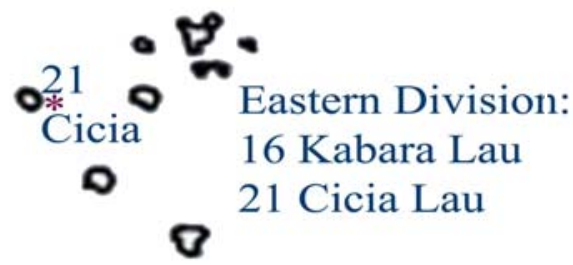 \\ 4 Kociriciri Nausori \\ 17 Tailevu \\ 19 Levuka \\ KANDAVU

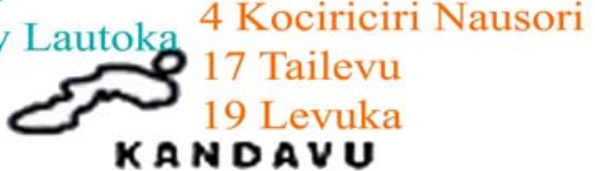 \\ LAU GROUP \\ 8) Sabara $^{6}$
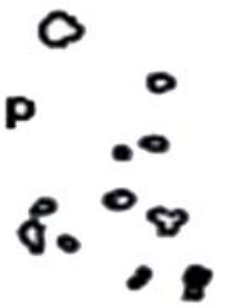

Fig. 1. The map of Fiji I slands with marked locations showing the origin of the honey samples. 
honey bees (Apis mellifera) and two processed Fijian honeys through measurement of the zones of inhibition in an agar well diffusion assay, with reference to phenol as a standard antiseptic, testing them against the clinical isolates from DFU. The minimum inhibitory concentrations (MIC) of the 32 honeys were also determined against the same isolates.

\section{Materials and methods}

\section{Honey Samples}

Thirty samples of raw honey were collected by the beekeepers and the National Apicultural Coordinator from different geographical regions in Fiji as shown on the map in Fig. 1. Two samples of processed honey were obtained from the supermarket. The samples represented prominent bee farming industries in Fiji. The floral sources of the honeys were identified by the beekeepers (Table.1). Two samples from different suppliers of the same floral source were analyzed for comparison purposes. All of the samples were stored at room temperature and in the dark for 2 months until they were tested.

\section{Antimicrobial Activity}

The procedure used for evaluating antimicrobial activity was described by Allen and colleagues but without the inclusion of catalase (Allen et al., 1991). Whereas that method used only $S$. aureus, in this study six clinical isolates were used. The test organisms: S. aureus, E. coli, P. aeruginosa, P. mirabilis, $K$. pneumoniae and $C$. albicans were isolated from DFU of patients from CWM Hospital. The information on their identities and antibiotic sensitivities was provided by the Head Microbiologist. The organisms were stored on plates at $4^{\circ} \mathrm{C}$. Cultures were also stored in glycerol at $-80^{\circ} \mathrm{C}$ and sub cultured when required.

Inoculum preparation: Each of the clinical isolates were inoculated into $10 \mathrm{ml}$ of Trypticase Soy broth and grown at $37^{\circ} \mathrm{C}$ for 18 hours. A further working culture was prepared by inoculating $200 \mu \mathrm{L}$ from the overnight culture into $10 \mathrm{~mL}$ of Trypticase Soy broth and adjusted to 0.5 McFarland Standard (equivalent to $10^{6}$ Colony Forming Unit $(\mathrm{CFU}) / \mathrm{mL}$ ), and diluted further to set an inoculum density of $1 \times 10^{4} \mathrm{CFU} / \mathrm{mL}$ which was used for the test.

Plate preparation: To prepare the assay plates $20 \mathrm{~mL}$ of nutrient agar (Merck) for each plate was sterilized and seeded with $100 \mu \mathrm{L}$ inoculum adjusted to $1 \times 10^{4} \mathrm{CFU} / \mathrm{mL}$.
Preparation of honey samples: A 40\% (v/v) stock was prepared which was further diluted to obtain other concentrations of $(20 \%$, $10 \%, 5 \%$, and $2.5 \%$ ) v/v respectively.

Preparation of phenol standards: Standards 1\% - 19\% were prepared from a $20 \% \mathrm{w} / \mathrm{v}$ solution of phenol (BDH analar grade reagent) in water.

Sample and standard application: Wells with similar spacing were cut into the agar. Each sample and standard was tested in triplicate by adding to each well.

Plate incubation: After application of samples and standards, the plates were incubated at $37^{\circ} \mathrm{C}$ for $24 \mathrm{hrs}$ compared to a control plate that had no honey. The zones of inhibition were observed for various concentrations of honey and phenol standards after the incubation period.

\section{Calculation of the antibacterial activity of honey}

The mean diameter of the clear zone around each phenol standard was measured and squared. From the graph of $\%$ phenol against the square of the mean diameter of the clear zone, the activity of each diluted honey sample was calculated. The activity was expressed as the equivalent phenol concentration (\% $\mathrm{w} / \mathrm{v})$.

\section{Minimum I nhibitory Concentration (MIC)}

The MIC was determined as described by Mulu, Belay \& Fetene (2004). This paper tested MIC of honey against all the clinical isolates except for C. albicans.

Mueller Hinton Agar (Merck) was sterilized and held in a water bath $\left(45-5040^{\circ} \mathrm{C}\right)$. Honeys were briefly heated to $40^{\circ} \mathrm{C}$ to reduce viscosity and known volumes of honey were measured into $20 \mathrm{~mL}$ of molten media to give final concentrations of $2.4 \%, 3.6 \%, 4.8 \%$, $5.9 \%, 7.0 \%$, and $9.1 \%(\mathrm{v} / \mathrm{v})$. The plate was poured, allowed to set and seeded with bacteria adjusted at $1 \times 10^{4} \mathrm{CFU} / \mathrm{mL}$ before incubation at $37^{\circ} \mathrm{C}$ for $24 \mathrm{~h}$. The plates were observed for growth and the results of the MIC were reported as the lowest concentration of honey that completely inhibited visible growth. For the plates where growth was visible, the results were recorded as $>9.1 \% \mathrm{v} / \mathrm{v}$ (highest concentration of honey tested). Plans were to select honeys with lower MIC values and include those in clinical trials, therefore the maximum concentration of honey used was $9.1 \%$. 
Table 1. Antimicrobial activities of Fijian Honeys against clinical isolates from DFU, measured by an agar well diffusion assay. The results are shown the concentration of a solution of phenol with the equivalent microbial activity. Values shown are the mean ( \pm SD) of three determinations. ND $=$ Not Detectable, (less than $4.1 \%(\mathrm{w} / \mathrm{v})$ phenol equivalent).

\begin{tabular}{|c|c|c|c|c|c|c|c|}
\hline \multicolumn{8}{|c|}{ Total Antimicrobial activity as \% (w/v) phenol equivalent } \\
\hline Sample & Floral Source & S.aureus & E.coli & P.aeruginosa & K.pneumoniae & P.mirabilis & C.albicans \\
\hline 1 & Mango & 4.9 & 6.4 & ND & 5.7 & ND & ND \\
\hline 2 & Coconut & 6.7 & 5.2 & ND & 5.7 & 5.2 & ND \\
\hline 3 & Lantana & 12.7 & 6.8 & 11.9 & 13.8 & ND & 5.8 \\
\hline 4 & Henna Plant & 5.1 & ND & ND & 7.2 & 5.8 & ND \\
\hline 5 & Mile a minute & ND & ND & ND & 6.1 & 7.6 & ND \\
\hline 6 & Mile a minute & ND & ND & ND & 7.3 & ND & ND \\
\hline 7 & Pawpaw & 9.1 & ND & ND & 11.3 & ND & ND \\
\hline 8 & Balsam & ND & 7.2 & ND & 5.7 & 4.8 & ND \\
\hline 9 & Bush Thumbergia & 12.4 & 1.3 & 6.9 & 5.7 & 5.6 & 4.9 \\
\hline 10 & Dilo & 8.0 & ND & ND & 4.8 & ND & ND \\
\hline 11 & Mango & 4.9 & 5.2 & 11.3 & ND & ND & ND \\
\hline 12 & Vaivai & 5.2 & 10.3 & 5.7 & 5.7 & ND & ND \\
\hline 13 & Dilo & 7.8 & ND & 7.6 & 5.2 & ND & ND \\
\hline 14 & Balsam & 5.6 & 4.7 & ND & 5.2 & ND & 4.2 \\
\hline 15 & Mint Weed & 13.5 & ND & 4.5 & 13.4 & ND & 4.3 \\
\hline 16 & Mint Weed & 14.5 & 11.0 & 4.8 & 5.7 & 6.8 & 6.8 \\
\hline 17 & Bush Thumbergia & 10.3 & ND & ND & 11.4 & 8.9 & 8.5 \\
\hline 18 & Lantana & 12.1 & 7.8 & 10.2 & 10.1 & 10.3 & 6.4 \\
\hline 19 & Pawpaw & 9.4 & 5.1 & 4.9 & 9.3 & 9.5 & 7.8 \\
\hline 20 & Passion Fruit & 4.9 & 13.6 & 5.4 & 13.4 & 8.2 & 8.7 \\
\hline 21 & Vaivai & 5.4 & 10.1 & 4.1 & 12.6 & 14.1 & 7.2 \\
\hline 22 & Marigold & 7.3 & 11.8 & 4.9 & 6.1 & 7.6 & 9.7 \\
\hline 23 & Orange & 9.9 & ND & 4.5 & 10.0 & 9.9 & 9.2 \\
\hline 24 & Coconut & 6.5 & ND & 8.1 & 11.1 & 5.9 & ND \\
\hline 25 & Hibiscus & 8.2 & 12.9 & ND & 7.8 & 6.1 & 5.5 \\
\hline 26 & Orange & 9.4 & 11.5 & 7.4 & 7.2 & ND & 4.9 \\
\hline 27 & Henna Plant & 5.0 & ND & 5.3 & 5.7 & 5.6 & 6.1 \\
\hline 28 & Hibiscus & 8.6 & ND & ND & ND & ND & 4.4 \\
\hline 29 & Marigold & 9.5 & ND & 4.9 & 5.4 & 4.7 & ND \\
\hline 30 & Passion Fruit & 4.8 & ND & 6.2 & 4.8 & ND & 4.7 \\
\hline 31 & Processed A & 5.3 & 6.5 & 4.7 & 4.9 & 6.1 & ND \\
\hline 32 & Processed B & 4.5 & 5.1 & ND & 5.3 & 8.9 & 5.9 \\
\hline Mean & - & 7.6 & 5.2 & 4.8 & 7.3 & 4.6 & 4.4 \\
\hline SD & - & 0.3 & 0.1 & 0.5 & 0.4 & 0.8 & 0.6 \\
\hline
\end{tabular}


Table 2. The Mean Inhibitory Concentrations (MIC) of Fijian Honeys as determined by the agar incorporation technique. The results are shown as the minimum concentration of each honey that gave complete inhibition of each isolate from DFU. The values $>9.1 \%$ indicate that there was no inhibition at the highest concentration tested.

\begin{tabular}{|c|c|c|c|c|c|c|c|}
\hline \multicolumn{8}{|c|}{ Mean I nhibitory Concentration (\% v/ v) } \\
\hline Sample & Floral Source & S.aureus & E.coli & P.aeruginosa & K.pneumoniae & P.mirabilis & C.albicans \\
\hline $\mathbf{1}$ & Mango & $>9.1$ & $>9.1$ & $>9.1$ & $>9.1$ & $>9.1$ & $>9.1$ \\
\hline 2 & Coconut & $>9.1$ & $>9.1$ & $>9.1$ & $>9.1$ & $>9.1$ & $>9.1$ \\
\hline 3 & Lantana & 9.1 & $>9.1$ & 4.8 & 7.0 & $>9.1$ & $>9.1$ \\
\hline 4 & Henna Plant & $>9.1$ & $>9.1$ & $>9.1$ & $>9.1$ & $>9.1$ & $>9.1$ \\
\hline 5 & Mile a minute & $>9.1$ & $>9.1$ & $>9.1$ & $>9.1$ & $>9.1$ & $>9.1$ \\
\hline 6 & Mile a minute & $>9.1$ & $>9.1$ & $>9.1$ & $>9.1$ & $>9.1$ & $>9.1$ \\
\hline 7 & Pawpaw & 9.1 & $>9.1$ & $>9.1$ & 9.1 & $>9.1$ & $>9.1$ \\
\hline 8 & Balsam & $>9.1$ & $>9.1$ & $>9.1$ & $>9.1$ & $>9.1$ & $>9.1$ \\
\hline 9 & Bush Thumbergia & 9.1 & $>9.1$ & $>9.1$ & $>9.1$ & $>9.1$ & $>9.1$ \\
\hline 10 & Dilo & $>9.1$ & $>9.1$ & $>9.1$ & $>9.1$ & $>9.1$ & $>9.1$ \\
\hline 11 & Mango & $>9.1$ & $>9.1$ & 5.9 & $>9.1$ & $>9.1$ & $>9.1$ \\
\hline 12 & Vaivai & $>9.1$ & $>9.1$ & $>9.1$ & $>9.1$ & $>9.1$ & $>9.1$ \\
\hline 13 & Dilo & $>9.1$ & $>9.1$ & $>9.1$ & $>9.1$ & $>9.1$ & $>9.1$ \\
\hline 14 & Balsam & $>9.1$ & $>9.1$ & $>9.1$ & $>9.1$ & $>9.1$ & $>9.1$ \\
\hline 15 & Mint Weed & 9.1 & $>9.1$ & $>9.1$ & 7.0 & $>9.1$ & $>9.1$ \\
\hline 16 & Mint Weed & 7.0 & 9.1 & $>9.1$ & $>9.1$ & $>9.1$ & $>9.1$ \\
\hline 17 & Bush Thumbergia & 9.1 & $>9.1$ & $>9.1$ & 9.1 & $>9.1$ & $>9.1$ \\
\hline 18 & Lantana & 9.1 & $>9.1$ & 7.0 & 9.1 & 9.1 & $>9.1$ \\
\hline 19 & Pawpaw & 9.1 & $>9.1$ & $>9.1$ & 9.1 & 9.1 & $>9.1$ \\
\hline 20 & Passion Fruit & $>9.1$ & 9.1 & $>9.1$ & 7.0 & $>9.1$ & $>9.1$ \\
\hline 21 & Vaivai & $>9.1$ & 9.1 & $>9.1$ & 9.1 & 7.0 & $>9.1$ \\
\hline 22 & Marigold & $>9.1$ & 9.1 & $>9.1$ & $>9.1$ & $>9.1$ & $>9.1$ \\
\hline 23 & Orange & 9.1 & $>9.1$ & $>9.1$ & 9.1 & 9.1 & $>9.1$ \\
\hline 24 & Coconut & $>9.1$ & $>9.1$ & $>9.1$ & 9.1 & $>9.1$ & $>9.1$ \\
\hline 25 & Hibiscus & $>9.1$ & 9.1 & $>9.1$ & $>9.1$ & $>9.1$ & $>9.1$ \\
\hline 26 & Orange & 9.1 & 9.1 & $>9.1$ & $>9.1$ & $>9.1$ & $>9.1$ \\
\hline 27 & Henna Plant & $>9.1$ & $>9.1$ & $>9.1$ & $>9.1$ & $>9.1$ & $>9.1$ \\
\hline 28 & Hibiscus & $>9.1$ & $>9.1$ & $>9.1$ & $>9.1$ & $>9.1$ & $>9.1$ \\
\hline 29 & Marigold & 9.1 & $>9.1$ & $>9.1$ & $>9.1$ & $>9.1$ & $>9.1$ \\
\hline 30 & Passion Fruit & $>9.1$ & $>9.1$ & $>9.1$ & $>9.1$ & $>9.1$ & $>9.1$ \\
\hline 31 & Processed A & $>9.1$ & $>9.1$ & $>9.1$ & $>9.1$ & $>9.1$ & $>9.1$ \\
\hline 32 & Processed B & $>9.1$ & $>9.1$ & $>9.1$ & $>9.1$ & $>9.1$ & $>9.1$ \\
\hline SD & - & 0.5 & 0.3 & 0.4 & 0.6 & 0.3 & 0.6 \\
\hline
\end{tabular}




\section{Results}

\section{Antimicrobial Activity}

The antimicrobial activity of the 32 Fijian honeys (natural and processed) against the clinical isolates of DFU is shown in Table 1, expressed as the concentration of phenol with activity equivalent to that of the undiluted honey (Allen et al., (1991). The lowest concentration of phenol standard which was able to produce detectable antimicrobial activity in this assay was $4.1 \%(\mathrm{w} / \mathrm{v})$. The absence of zones of inhibition indicated that the activity could not be detected (ND) for these honeys as it was lower than $4.1 \%(\mathrm{w} / \mathrm{v})$ phenol equivalent.

\section{Minimum I nhibitory Concentration}

The MIC's of the 32 Fijian honeys tested against the clinical isolates from DFU showed marked variation between microorganisms (Table 2). The 2 processed honeys did not inhibit any of the microbes at $9.1 \% \mathrm{v} / \mathrm{v}$, which is the highest concentration used for this assay. None of the honeys were able to inhibit C.albicans at $9.1 \%(\mathrm{v} / \mathrm{v})$. The MIC values of the 30 natural honeys against the six microbes were between 4.8 and higher than $9.1 \%(\mathrm{v} / \mathrm{v})$.

\section{Discussion}

In this study we have demonstrated that all the 32 Fijian honeys display antimicrobial activity against clinical isolates of DFU. More than half of the honeys demonstrated activity equivalent to that of phenol between $4 \%$ and $12 \%(\mathrm{w} / \mathrm{v})$ (Table 1$)$. The MIC values indicate that most of the 30 natural honeys (Table 2) failed to inhibit the DFU clinical isolates tested here, (19 honeys against $S$. aureus, 24 honeys against $E$. coli, 27 honeys against $P$. aeruginosa, 20 honeys against $K$. pneumoniae, 26 honeys against $P$. mirabilis, and all the 30 honeys against $C$. albicans). The two processed honeys did not inhibit any of the microbes from DFU at the maximum concentration tested $(9.1 \% \mathrm{v} / \mathrm{v})$. These values for the antibacterial activity of Fijian honeys tested against $S$. aureus can be compared with those obtained by Allen et al. (1991) from testing 345 samples of New Zealand honeys by the same method. They found the median MIC value to be equivalent to $13.6 \%(\mathrm{w} / \mathrm{v})$ phenol. The mean value from the testing against $S$. aureus in the present study, equivalent to $7.6 \%$ phenol, indicates that Fijian honeys are not as potently antibacterial as New Zealand honeys. This is also indicated by the finding that the most active of the 30 samples of unprocessed Fijian honey had an activity equivalent to only $14.5 \%(\mathrm{w} / \mathrm{v})$ phenol, little more than the median activity for the New Zealand honeys. However, a larger number of samples would have to be tested before this could be concluded with certainty.

The MIC values found in the present study for Fijian honeys can be compared with those found by other authors for other honeys tested against $S$. aureus and $P$. aeruginosa, the dominant microbes in DFU (Bansal et al., 2008). Cooper et al. (1999) used a manuka honey (non-peroxide activity) and a pasture honey (hydrogen peroxide activity), each with a near median level of activity for that type of activity, testing it against 58 strains of coagulase-positive S. aureus, and found the MIC to range from $2 \%$ to $3 \%(\mathrm{v} / \mathrm{v})$ for the manuka honey and $3 \%$ to $4 \%(\mathrm{v} / \mathrm{v})$ for the pasture honey. Similar honeys were also tested against 20 clinical isolates of Pseudomonas spp from infected wounds (Cooper, Molan and Harding, 2002) and against 17 strains of $P$. aeruginosa isolated from infected burns. (Cooper, Halas and Molan, 2002). Mean values for the MIC for both types of honey were $7 \%(\mathrm{v} / \mathrm{v})$ for both studies. In comparison, the MIC values found in the present study in testing against $S$. aureus ranged from $7.0->9.1 \%(\mathrm{v} / \mathrm{v})$ and against $P$. aeruginosa were in the range $4.8->9.1 \% \mathrm{v} / \mathrm{v}$. The comparison again indicates that the Fijian honeys do not have a high level of antibacterial activity. However, the MIC values found indicate that it would be possible to select Fijian honeys that would completely inhibit the growth of bacteria even if the honey became diluted ten-fold when in use on infected ulcers.

A clinical trial would be needed using Fijian honey to discover whether the locally produced honey is suitable for resolving the problem of infected DFU in Fiji. There is no evidence from randomized controlled trials to evaluate the effectiveness of honey in the eradication of infection or healing of DFU. However, it was reported by Sahel (2004) that honey treatment of DFU gave better control of infection and reduced mean healing time and amputation rates, much better than that achieved with Povidone iodine / hydrogen peroxide. Gethin and Cowman (2008) recruited 180 patients with venous leg ulcers. The patients represented some with diabetic ulcers. It was observed that manuka honey increased incidence of healing, gave effective desloughing and a lower incidence of infection than the control. In a non-comparative study of the use of honey as a wound dressing, Efem (1988) treated wounds of various etiology, including diabetic ulcers, with honey therapy. The results of this study indicated that honey promoted granulation and epithelization of the wounds, reduced odour and had a dehydrating effect on the wounds. Case studies have also shown that honey has rapid healing effects on DFU (Eddy et al., 2008).

The faster healing of DFU dressed with honey also may result from the anti-inflammatory and de-sloughing effects of honey. There are numerous reports of these effects being observed clinically in a variety of types of wound as a reduction in odema and pain (Molan, 1999) and improvement in healing outcomes (Gethin \& Cowman, 2008). These beneficial effects of honey, and its lack of adverse effects on wounds (Molan, 1999), considered along with the findings from the present study, indicate that Fijian honeys can be regarded as a possible treatment option for DFU. The authors are currently recruiting participants for a randomized controlled trial to assess the efficacy of honey against DFU. 


\section{Acknowledgments}

This work was funded by the London Insulin Dependent Diabetes Trust (IDDT). We thank the CWM Hospital, Microbiology Department who kindly supplied us with the isolates of diabetic foot ulcers. We wish to thank Mr. Kamal Prasad, Apicultural Coordinator, Ministry of Agriculture Fiji for liasing with the bee-keepers and providing us with the honey samples from different regions in Fiji.

\section{References}

ALLEN, K L; MOLAN, P C; REID, G M (1991) A survey of the antibacterial activity of some New Zealand honeys. Journal of Pharmacy and Pharmacology 43(12): 817- 822.

AL- WAILI, N S (2004) Investigating the antimicrobial activity of natural honey and its effects on the pathogenic bacterial infections of surgical wounds and conjunctiva. Journal of Medicinal Food 7(2): 210-222.

BANSAL, E; GARG, A; BHATIA, S, et al (2008) Spectrum of microbial flora in diabetic foot ulcers. Indian Journal of Pathology and Microbiology 51(2): 204-208.

BASUALDO, C; SGROY, V; FINOLA, M S; MARIOLI, J M (2007) Comparison of the antibacterial activity of honey from different provenance against bacteria usually isolated from skin wounds. Veterinary Microbiology 124: 375-381.

BOUKRAA, L; NIAR, A (2007) Sahara honey show higher potency against Pseudomonas aeruginosa compared to north Algerian types of honey. Journal of Medicinal Food 10(4): 712- 714.

BRODSKY, J W; SCHNEILDER, C (1991) Diabetic Foot Infections. Orthopedic Clinical North American Journal 22: 472-489.

CHINCHOLIKAR, D A; PAL, R B (2002) Study of fungal and bacteriological infections of the diabetic foot. Indian Journal of Pathology and Microbiology 45: 15-22.

COOPER, R A; HALAS, E; MOLAN, P C (2002) The efficacy of honey in inhibiting strains of Pseudomonas aeruginosa from infected burns. Journal of Burn Care \& Rehabilitation 23(6): 366-370.

COOPER, RA; MOLAN, PC (1999) The use of honey as an antiseptic in managing Pseudomonas infection. Journal of Wound Care 8 (4): 161-164.

COOPER, R A; MOLAN, P C; HARDING, K G (2002) The sensitivity to honey of Gram- positive cocci of clinical significance isolated from wounds. Journal of Applied Microbiology 93: 857-863.

COOPER, R A; MOLAN, P C; HARDING, K G (1999) Antibacterial activity of honey against strains of Staphylococcus aureus from infected wounds. Journal of the Royal Society of Medicine 92 (6): 283-285.

CRIADO, E; DE STEFANO, A A; KEAGY, B A; UPCHURCH, G R Jr; JOHNSON, G Jr (1992) The course of severe foot infection in patients with diabetes. Surgery Gynecology \& Obstetrics 175: 135-140.

EDDY, J J; GIDEONSEN, M D; MACK, G P (2008) Practical Considerations of using topical honey for neuropathic diabetic foot ulcers: a review. Wisconsin Medical Journal 107(4): 187-190.
EFEM, S E E (1988) Clinical observations on the wound healing properties of honey. British Journal of Surgery 75: 679-681.

ESTRADA, H; GAMBOA, M; MDEL, M; ARIAS, L; CHAVES, C (2005) Evaluation of the antimicrobial action of honey against Staphylococcus aureus, Staphylococcus epidermidis, Pseudomonas aeruginosa, Escherichia coli, Salmonella enteritidis, Listeria monocytogenes and Aspergillus niger. Evaluation of its microbiological charge. Archivos latinoamericanos de nutrición 55 (2): 167-171.

FANGIO, M F; IURLINA, M O; FRITZ, R (2007) Antimicrobial activity of honey of the southeast of Buenos Aires Province against Escherichia coli. Revista Argentina De Microbiologia 39(2): 120-123.

GETHIN, G; COWMAN,S (2008)Manuka honey vs. hydrogel- a prospective, open label, multicentre, randomized controlled trial to compare desloughing efficacy and healing outcomes in venous ulcers. Journal of Clinical Nursing 10: 1365-2702.

JOHNSON, D W; VAN EPS, C; MUDGE, D W; WIGGINS, K J; ARMSTRONG, K; HAWLEY, C W; CAMPBELL, S F; ISBEL, N M; NIMMO, G R; GIBBS, H (2005) Randomized, controlled trial of topical exit-site application of honey (Medihoney) versus mupirocin for the prevention of catheter- associated infections in hemodialysis patients. Journal of American Society of Nephrology 16(5): 1456-1462.

JULL, A; WALKER, N; PARAG, V; MOLAN, P; RODGERS, A (2008) Randomized clinical trial of honey impregnated dressings for venous leg ulcers. British Journal of Surgery 295: 175-182.

MERCAN, N A; GUVENSEN, A; CELIK, A; KATICIOGLU, H (2007) Antimicrobial activity and pollen composition of honey samples collected from different provinces in Turkey. Journal of Natural Product Research 21(3): 187-195.

MIORIN, P L; LEVY JUNIOR, N C; CUSTODIO, A R; BRETZ, W A; MARCUCCI, M C (2003) Antibacterial activity of honey and propolis from Apis mellifera and Tetragonisca angustula against staphylococcus aureus. Journal of Applied Microbiology 95(5): 913-920.

MOLAN, P C and BETTS, J A (2004) Clinical usage of honey as a wound dressing: an update. Journal of Wound Care 13(9): 5-28.

MOLAN, P C (1999) The role of honey in the management of wounds. Journal of Wound Care 8(8): 423- 426.

MOLAN, P C (1992) The antibacterial activity of honey. 1. The nature of antibacterial activity. Bee World 73(1): 5-28.

MOLAN, P C; RUSSELL, K M (1988) Non-peroxide antibacterial activity in some New Zealand honeys. Journal of Apicultural Research 27(1): 62-67.

MULLA, V; MENON, T (2007) Bactericidal activity of different types of honey against clinical and environmental isolates of Pseudomonas aeruginosa. Journal of Alternative and Complementary Medicine 13 (4): 439-441.

MULU, A; BELAY, T; FETENE, D (2004) In vitro assessment of antimicrobial potential of honey on common human pathogens. Ethiopian Journal of Health Development 18(2): 107-111.

OLUWATOSIN, O M; OLABANJI, J K; OLUWATOSIN, O A; TIJANI, L A; ONYECHI, H U (2000) A comparison of topical honey and phenytoin in the treatment of chronic leg ulcers. African Journal of Medical Sciences 29(1): 31-34.

PATHARE, N A; BAL, A; TALALKAR, G V; ANTANI, D U (1998) Diabetic Foot Infections: A study of microorganisms associated with different Wagner Grades. Indian Journal of Pathology and Microbiology 41: 437-441. 
PAYNE, D J; GWYNN, M N; HOLMES, D J; POMPLIANO, D L (2007) Drugs for bad bugs: confronting the challenges of antibacterial discovery. Nature Reviews Drug Discovery 6: 29-40.

RAMANI, A; RAMANI, R; SHIVANANDAN, P G; KUNDAG, G N (1991) Bacteriology of Diabetic Foot Ulcers. Indian Journal of Pathology and Microbiology 34: 81-87.

SAHEL, K H (2004) The role of honey in the management of diabetic foot ulcers. Journal of Research in Medical Sciences 11(2): 20-22.

SUBRAMANIUM, M (1993) Honey impregnated gauze versus polyurethane film (OpSite) in the treatment of burns- a prospective randomized study. British Journal of Plastic Surgery 46(4): 322-323.

TENTOLOURIS, N; JUDE, E B; SMIRNOF, I; KNOWLES, E A; BOULTON, A J M (1999) Methicillin-resistant Staphylococcus aureus: an increasing problem in a diabetic foot clinic. Diabetic Medicine 16: 767-771
VAN DER WEYDEN, E A (2003) The use of honey for the treatment of two patients with pressure ulcers. British Journal of Community Nursing 8(12): S14-S20.

VISWANATHAN, $V$; JASMINE, J J; SNEHALATHA, C; RAMACHANDRAN, A (2002) Prevalence of pathogens in Diabetic Foot Infection in South India type 2 diabetic patients. Journal of the Association of Physicians of India 50: 1013-1016.

WEHEIDA, S M; NAGUBIB, H H; EL-BANNA H M; MARZOUK, S (1991) Comparing the effects of two dressing techniques on healing of low grade pressure ulcer. Journal of Medical Research Institute Alexandria 12(2): 259-278.

WHITE, J W; SUBERS, M H; SCHEPARTZ, A I (1963) The identification of inhibine, the antibacterial factor in honey, as hydrogen peroxide and its origin in a honey glucose-oxidase system. Biochimical et Biophysica Acta 73: 57-70. 